\title{
COMPARISON OF THE MINERAL COMPOSITION OF 12 STANDARD NUTRIENT SOLUTIONS
}

De Rijck G. and Schrevens E.

Faculty of Agricultural and Applied Biological Sciences

Department of Applied Plant Sciences K.U.Leuven

Willem de Croylaan 42, B-3001 Heverlee (Belgium)

\section{$\underline{\text { ABSTRACT }}$}

In the past, a large number of standard nutrient solutions has been devised. To investigate if there is an essential difference between these standard solutions, the mineral composition of 12 standard nutrient solutions formulated between 1865 and 1994 are compared with each other. Half of these standard solutions contains ammonium in a millimolar range.

The effect of elemental speciation of the micronutrients in the 12 standard solutions on bioavailability is compared. The macronutrient composition is represented in trilinear co-ordinates, making a clear comparison of the proportions of both the cations and the anions possible. Also the $\mathrm{pH}$ and the total amount of ions present are compared.

\section{INTRODUCTION}

Julius von Sachs (1860) was one of the first in developing a standard method for growing plants in a dilute aqueous solution of various salts. In this way it was possible to investigate the nutritional needs of crops under laboratory circumstances. During the period 1860 to 1900 , the preparation of laboratory water cultures became more or less standardised, and the methods of using them in experimental studies well established. 
In 1865 Knop formulated his standard nutrient solution, supplying calcium as calciumnitrate and iron as ironphosphate and three years later adjusted the solution to include ironchloride.

Pfeffer in 1900 and von der Crone in 1902 each formulated their standard nutrient solution.

It took until after the turn of the century before attention was paid to the physical effects of artificial cultures upon plant growth, with special considerations given to osmotic properties of the solution. As cited by Hewitt (1966), W.E. Tottingham in 1914 was one of the first in doing quantitative chemical and physiological studies of various water culture solutions.

In the past, a large number of standard nutrient solutions has been devised. For a great deal of these standard solutions, an exact description of the mineral composition can not be found in literature. This research compares the mineral composition of 12 standard nutrient solutions formulated between 1865 and 1994.

\section{MATERIAL AND METHODS}

The mineral composition of the 12 standard nutrient solutions is represented in table 1 . Half of the standard solutions under study contain ammonium in a millimolar range. The micronutrients and the macronutrients of the standard solutions are considered separately.

\section{$\underline{\text { Micronutrients }}$}

Elemental speciation in nutrient solutions mainly affects the micronutrients. Therefore elemental speciation has to be taken into account in describing the micronutrient composition of nutrient solutions. The term speciation indicates the distribution of elements among their various chemical and physical forms like: free ions, soluble complexes, chelates, ionpairs, solid and gaseous phases and different oxidation states, all of which influence their reactivity, mobility and bioavailability.

For each standard solution speciation calculations are carried out, using the computer speciation program Geochem PC version 2.0 (Parker et al., 1995). 


\section{Macronutrients}

A nutrient solution can be considered as an aqueous solution of inorganic ions. According to Steiner (1961), the chemical composition of a nutrient solution is determined by the relative cation proportions, the relative anion proportions, the total ionic concentration and the $\mathrm{pH}$. The $\mathrm{pH}$ of an aqueous solution is determined by the initial concentration of acids and bases. Once the relative anion proportions, the relative cation proportions and the total milli-equivalent concentration are determined, the $\mathrm{pH}$ is also determined. This means that the $\mathrm{pH}$ is an inherent property of the mineral composition of the nutrient solution, and can not be changed independently.

In general, nutrient solutions for plant production consist, beside of the essential micronutrients, of six essential macronutrients: three cations : potassium, calcium and magnesium and three anions: nitrate, dihydrogenphosphate and sulphate. Some nutrient solutions also contain ammonia in a millimolar range.

Nutrients are put in solution by dissolving salts. This imposes the ionic balance constraint on nutrient solutions (Schrevens, 1988a):

$\Sigma$ cation equivalents $=\Sigma$ anions equivalents

Simplifying a nutrient solution to the six essential macronutrients, neglecting hydrogen and hydroxide ions and possible dissociation forms of $\mathrm{H}_{2} \mathrm{PO}_{4}{ }^{-}$renders:

$$
\left[\mathrm{K}^{+}\right]+\left[\mathrm{Ca}^{2+}\right]+\left[\mathrm{Mg}^{2+}\right]+\left[\mathrm{NH}_{4}^{+}\right]=\left[\mathrm{NO}_{3}{ }^{-}\right]+\left[\mathrm{H}_{2} \mathrm{PO}_{4}^{-}\right]+\left[\mathrm{SO}_{4}{ }^{2-}\right]=\mathrm{C} / 2
$$

With $\mathrm{K}^{+}, \mathrm{Ca}^{2+}, \mathrm{Mg}^{2+}, \mathrm{NH}_{4}{ }^{+}, \mathrm{NO}_{3}{ }^{-}, \mathrm{H}_{2} \mathrm{PO}_{4}{ }^{-}$and $\mathrm{SO}_{4}{ }^{2-}$ expressed in milli-equivalents/1 and $\mathrm{C}$ being the total amount of both cations and anions in milli-equivalents/l.

Dividing the amount of milli-equivalents/l of each ion by half of the total milliequivalent concentration, results in the proportion that each cation or anion represents of the total amount of cations or anions present. In this way nutrient solutions can be represented by the proportions of the cations, the proportions of the anions and the total milli-equivalent concentration.

If the proportion of two cations or anions is set, the proportion of the third cation or anion is also determined. This makes it possible to represent both the cation and the anion composition of a nutrient solution as a single point in trilinear co-ordinates. 
The proportion of each ion corresponds to the length of the perpendiculars from each point to the 3 sides. The ratio of the 3 ions is determined by the relative position of the point within the triangle. The use of relative proportions of ions makes both a straightforward comparison of the composition of nutrient solutions and a graphical representation of their position in an equilateral triangle possible.

If only 3 cation (anions) are present, they can be represented in a two dimensional equilateral triangle. For the nutrient solutions containing also ammonia in a millimolar range, there are four cations present. In this case the cation composition can be presented as a single point in a three dimensional tetraeder.

In figure 1 the cation proportions of the standard solutions, not containing ammonium, are represented as single points in a simplex. For the solutions, containing ammonium, the position of the points in the 3 dimensional tetraeder is projected to the 2 dimensional groundsurface (equilateral triangle) of the tetraeder, where $\mathrm{NH}_{4}{ }^{+}$equals zero. In that point the proportion ammonium is proportionate with the surface of the circle (Figure $1)$.

The mean cation and anion composition of the 12 standard solutions is calculated. For each standard solution also the Euclidean distance to this mean composition is calculated.

Since a specific mineral composition corresponds with a specific $\mathrm{pH}$, the $\mathrm{pH}$ of each standard solutions is calculated.

\section{RESULTS AND DISCUSSION}

\section{$\underline{\text { Micronutrients }}$}

Knop's standard solution (Table 1), formulated in 1865, lacks Mn, Cu, Zn, B, Mo and Cl. The same elements including iron are absent in the gravel culture solution from Japan. These essential elements were probably in adequate amounts present as contaminants in the salts and substrates used. 
According to the computer speciation program Geochem PC version 2.0 (Parker et al., $1995)$, in all nutrient solutions containing iron, $\mathrm{Fe}\left(\mathrm{PO}_{4}\right) \cdot 2 \mathrm{H}_{2} \mathrm{O}$ (strengite) precipitates (Table 2). The precipitated iron is not available for uptake by plants

In the standard solutions where iron is not supplied bound to a chelating agent (Knop, Penningsfeld North Africa, Penningsfeld Carnations, and Shive and Robbins) iron is almost completely precipitated. Adding iron bound to citrate or a synthetic chelate like EDTA (ethylenediaminetetraacetic acid), HEDTA (hydroxyethylethylenediaminetriacetic acid) or DTPA (Diethylenetriaminepenta-acetic acid) keeps iron better dissolved and bioavailable, but can not completely prevent precipitation.

By chelating iron (ferric) with citrate (Citr) (Arnon and Hoagland), the amount of iron precipitated can be reduced to $87.8 \%$ of the amount of iron supplied (Table 2).

Supplying iron bound to a synthetic chelate as EDTA, HEDTA or DTPA reduces the amount of precipitated iron to 4 to $6.9 \%$.

The amount of iron displaced from the synthetic chelate depends upon the $\mathrm{pH}$ of the nutrient solution, the stability of the iron chelate and the stability of other metal complexes that are formed (Halvorson, 1971). The chelating power of some synthetic chelates for $\mathrm{Fe}^{3+}$ is represented in table 3 (Norvell, 1972).

The higher the stability constant of the chelate, the stronger chelate and iron are bound. A high chelate stability results in less iron precipitation. Chelates like EDDHA, DTPA and CDTA have a strong affinity for iron (Table 3). Other chelates like NTA have only a low affinity for iron, resulting in iron precipitation and the formation of other cation chelates.

Adding iron chelates to nutrient solutions, some of the $\mathrm{Fe}^{3+}$ dissociates from the chelate. The free chelating agent equilibrates and associates with other metals in the solution. In this way synthetic chelates form complexes with $\mathrm{Cu}, \mathrm{Zn}, \mathrm{Mn}, \mathrm{Ca}$ and $\mathrm{Mg}$ and possibly compete with plants for the uptake of metals other than iron from the nutrient solution (Halvorson, 1971). According to Guin et al. (1963), the extent of iron displacement from the chelate by copper and zinc, is $\mathrm{pH}$ and chelate dependent. 
If synthetic chelates like EDTA, HEDTA and DTPA are used, 96.5 to $100 \%$ of the $\mathrm{Cu}$ present is complexed with the chelate (Table 2). If Citr is used (Arnon and Hoagland), this is reduced to $40 \%$. If no chelating agent is present 86 to $90 \%$ of the $\mathrm{Cu}$ is present as a free ion. The chelating power of some synthetic chelates for $\mathrm{Cu}^{2+}$ is represented in table 3. In Penningsfeld's North African solution $\mathrm{Cu}$ is present in a concentration as high as $10 \mathrm{micromol} / \mathrm{l}$, while the $\mathrm{Cu}$ concentration in the other solutions varies between 0 and $0.75 \mathrm{micromol} / 1$. Furthermore, this solution does not contain a chelating agent, so supplying this standard solution plant roots will experience a high free $\mathrm{Cu}^{2+}$ concentration.

According to the chelate used, different percentages of the amount of zinc present form a complex with the chelate (Table 2). Especially HEDTA in the standard solution binds a high percentage (99.2\%) of the $\mathrm{Zn}$ present, while Citr has only a low affinity for $\mathrm{Zn}$. The chelating power of some synthetic chelates for $\mathrm{Zn}^{2+}$ is represented in table 3 .

The standard solutions of the Research Centre for Soilless Cultures and of Cooper contain a high manganese concentration of respectively 43.7 and 36 micromol/1. Almost no manganese binds to chelating agents, except to HEDTA (7.7 \%) in the standard solution of the Research Centre for Soilless Cultures.

The micro-elements Mo and B are present in nutrient solutions both as the anions $\mathrm{MoO}_{4}{ }^{2-}$ and $\mathrm{B}(\mathrm{OH})_{4}{ }^{-}$and as polyanions. Because of their negative charge they can not bind with the negatively charged chelating agent. Penningsfeld's North African solution contains a high Mo concentration, while his carnation solution contains a high B concentration.

\section{Macronutrients}

All standard solutions are clustered together in the cation factor space, except Penningsfeld's North African solution and Shive and Robbins' solution (Figure 1). The mean cation composition of these 12 standard solutions contains a potassium, calcium, magnesium and ammonium proportion of respectively $0.35,0.43,0.19$ and 0.03 .

In the anion factor space the standard solutions are grouped together except the standard solutions of Shive and Robbins, Hacskalyo and Steiner (Figure 2). These three 
solutions are positioned at a higher sulphate and a lower nitrate proportion. All standard solutions are positioned at a low dihydrogenphosphate proportion and at a high nitrate proportion. The mean anion composition of these standard solutions contains a nitrate, dihydrogenphosphate and sulphate proportion of respectively $0.69,0.10$ and 0.21 .

The standard solutions of Penningsfeld carnation and Cooper are positioned closest to the overall mean of the standard solutions, while the standard solutions of Shive and Robbins and Penningsfeld North Africa are furthest removed, 0.35 and 0.31 proportions respectively (Table 4).

\section{$\mathrm{pH}$ and total ionic concentration}

Table 5 represents the $\mathrm{pH}$ and the amount of nutrients present in the standard solutions. In commercial practice however, the nutrient solutions are supplied and controlled at a certain electric conductivity (EC) and $\mathrm{pH}$. Monitoring the $\mathrm{pH}$ of the nutrient solutions, using an acid or a base, changes the nutritional composition.

The $\mathrm{pH}$ of the 12 standard solutions (Table 5) varies between 4.2 (Penningsfeld North Africa and Research Centre for Soilless Cultures) and 5.3 (Steiner), according to the amount of dihydrogenphosphate and ammonium present.

The total ionic concentration varies from $14.7 \mathrm{mmol} / 1$ (Penningsfeld North Africa) to $41.31 \mathrm{mmol} / 1$ (Research Centre for Soilless Cultures) or from 17.37 to $51.71 \mathrm{meq} / \mathrm{l}$.

\section{CONCLUSIONS}

In general in hydroponic plant nutritional research, as well as in commercial hydroponic plant cropping, it is assumed that all the nutrients are present in the nutrient solution as free ions. This view does not take into account the dissociation, complexation and precipitation reactions, occurring in nutrient solutions. These chemical reactions impact elemental speciation and bioavailability. As a result plants will experience a completely different nutritional composition.

Elemental speciation in nutrient solutions mainly affects the micronutrients. In all nutrient solutions containing iron, $\mathrm{Fe}\left(\mathrm{PO}_{4}\right) \cdot 2 \mathrm{H}_{2} \mathrm{O}$ (strengite) precipitates, even when 
iron is applied as a chelate. As a function of the $\mathrm{pH}$ and the chelate some of the $\mathrm{Fe}^{3+}$ dissociates from the chelate. The free chelate competes with plants for the uptake of metals other than iron from the nutrient solution (Halvorson, 1971). The released chelating agent equilibrates with metals like $\mathrm{Cu}, \mathrm{Mn}, \mathrm{Zn}, \mathrm{Ca}, \mathrm{Mg}, . .$. , forming their respective metal complexes and reducing their free concentration.

In their experiments with mustard plants Dekock et al. (1957) found that adding chelating agents to a nutrient solution reduced the concentration of $\mathrm{Zn}$ and $\mathrm{Cu}$ in the leaves.

Although there are some differences between the concentrations of the macronutrients, the relative proportions of both the cations and the anions of the 12 standard solutions are similar.

The $\mathrm{pH}$ of the 12 standard solutions is a property that is inherent to their composition and varies between 4.2 and 5.3. In commercial practice however the $\mathrm{pH}$ of a nutrient solution is controlled at a certain level, adding a strong acid or a strong base. This results in a changed relative proportion of both cations and anions.

\section{REFERENCES}

Dekock, P.C. and R.L. Mitchell, 1957. Uptake of chelated metals by plants. Soil Sci. 84:54-62.

Norvell, W.A., 1972. Equilibria of metal chelates in soil solution. in J.J. Mortvedt, P.M. Giordano and W.L. Lindsay, Micronutrients in Agriculture

Guinn, G. and H.E. Joham, 1963. Displacement of iron from ferric ethylenediaminetetra-acetic acid and ferric hydroxyethylethylenediamine-triacetic acid by copper and zinc. Soil Sci. 95:101-104.

Halvorson, A.D., 1971. Chelation and availability of metal ions in nutrient solutions. $\mathrm{Ph}$. D. thesis, Agronomy Department, Colorado State University.

Hewitt, E.J., 1966. Sand and water culture methods used in the study of plant nutrition. Technical communication No 22 (revised). Commonwealth Bureau of Horticulture and Plantation Crops, East malling, Maidstone, Kent, England. 
Parker, D.R., W.A. Norvell, and R.L. Chaney, 1995. GEOCHEM-PC: A chemical speciation program for IBM and compatible personal computers. In: Loeppert, R.H. et al. (ed.) Chemical equilibrium and reaction models. SSSA Spec. Publ. 42, SSSA, ASA, Madison, WI. 253-269.

Schrevens, E., 1988a. Design and analysis of mixture systems: Application in hydroponic plant nutritional research. PhD thesis. Katholieke Universiteit Leuven.

Schrevens, E., D. Lamberts, L. Lettani and F. Verberne, 1988b. Chloride effects on strawberry. Int. strawberry symposium, Cesena, Italy. Acta Hort. 265:285-290.

Steiner, A.A., 1961. A universal method for preparing nutrient solutions of a certain desired composition. Plant and Soil 15 no 2:134-154.

Tottingham, W.E., 1926. A quantitative chemical and physiological study of nutrient solutions for plant cultures. Physiol. Res. 1:133 (cited by Hewitt 1966). 
TABLE 1. Mineral composition of the 12 standard solutions

\begin{tabular}{|c|c|c|c|c|c|c|}
\hline $\begin{array}{l}\text { Nutrient } \\
\mathrm{mmol} / \mathrm{l}\end{array}$ & $\begin{array}{l}\text { Knop } \\
1865\end{array}$ & $\begin{array}{l}\text { Pennings- } \\
\text { feld North } \\
\text { Africa }\end{array}$ & $\begin{array}{l}\text { Pennings- } \\
\text { feld } \\
\text { Carnations }\end{array}$ & $\begin{array}{l}\text { Gravel } \\
\text { culture } \\
\text { Japan }\end{array}$ & $\begin{array}{l}\text { Arnon and } \\
\text { Hoagland } \\
1940\end{array}$ & $\begin{array}{l}\text { Dennisch R. } \\
\text { Hoagland } \\
\text { USA }\end{array}$ \\
\hline$\overline{\mathrm{K}^{+}}$ & 3.4 & 4.79 & 6.17 & 8 & 6.04 & 6.07 \\
\hline $\mathrm{Ca}^{2+}$ & 3.4 & 0.9 & 3.72 & 4.08 & 5.0 & 4.0 \\
\hline $\mathrm{Mg}^{2+}$ & 0.81 & 0.77 & 1.53 & 2.03 & 2.0 & 1.0 \\
\hline $\mathrm{NH}_{4}^{+}$ & 0 & 0.35 & 0.15 & 1.35 & 0 & 2.0 \\
\hline $\mathrm{Na}^{+}$ & 0 & 0.01 & 0.05 & 0.02 & 0 & 0.02 \\
\hline $\mathrm{Fe}^{3+}$ & 0.66 & 0.05 & 0.072 & 0 & 0.0258 & 0.02 \\
\hline $\mathrm{Mn}^{2+}$ & 0 & 0.0112 & 0.0224 & 0 & 0.0091 & 0.002 \\
\hline $\mathrm{Cu}^{2+}$ & 0 & 0.001 & 0.0002 & 0 & 0.0003 & 0.0005 \\
\hline $\mathrm{Zn}^{2+}$ & 0 & 0.0001 & 0.0001 & 0 & 0.0008 & 0.002 \\
\hline $\mathrm{NO}_{3}^{-}$ & 8.84 & 5.53 & 11.53 & 16.18 & 15.0 & 14.0 \\
\hline $\mathrm{H}_{2} \mathrm{PO}_{4}^{-}$ & 3.34 & 1.38 & 2.09 & 1.35 & 1.0 & 2.0 \\
\hline $\mathrm{SO}_{4}{ }^{2-}$ & 0.81 & 0.87 & 1.70 & 2.03 & 2. & 1. \\
\hline $\mathrm{Cl}^{-}$ & 0 & 0 & 0 & 0 & 0.018 & 0.05 \\
\hline $\mathrm{B}(\mathrm{OH})_{4}^{-}$ & 0 & 0.026 & 0.11 & 0 & 0.0422 & 0.025 \\
\hline $\mathrm{MoO}_{4}{ }^{2-}$ & 0 & 0.0043 & 0 & 0 & 0.0001 & 0.0005 \\
\hline EDTA & 0 & 0 & 0 & 0 & 0 & 0.02 \\
\hline Citrate & 0 & 0 & 0 & 0 & 0.0258 & 0 \\
\hline $\begin{array}{l}\text { Nutrient } \\
\mathrm{mmol} / 1\end{array}$ & $\begin{array}{l}\text { Shive and } \\
\text { Robbins } \\
1942 \\
\end{array}$ & $\begin{array}{l}\text { Hacskalyo } \\
1961\end{array}$ & $\begin{array}{l}\text { Steiner } \\
1961\end{array}$ & $\begin{array}{l}\text { Cooper } \\
1979\end{array}$ & $\begin{array}{l}\text { Research } \\
\text { Centre Soil- } \\
\text { less Cultures }\end{array}$ & $\begin{array}{l}\text { Naaldwijk } \\
\text { cucumber }\end{array}$ \\
\hline$\overline{\mathrm{K}^{+}}$ & 2.29 & 4.03 & 6.69 & 7.73 & 11.0 & 8. \\
\hline $\mathrm{Ca}^{2+}$ & 4.02 & 3 & 4.61 & 4.30 & 5.5 & 4.0 \\
\hline $\mathrm{Mg}^{2+}$ & 2.30 & 2 & 2.02 & 2.08 & 1.5 & 1.4 \\
\hline $\mathrm{NH}_{4}^{+}$ & 1.40 & 0 & 0 & 0.002 & 0.0005 & 1.25 \\
\hline $\mathrm{Na}^{+}$ & 0 & 0.09 & 0.02 & 0.03 & 0.38 & 0.03 \\
\hline $\mathrm{Fe}^{3+}$ & 0.02 & 0.09 & 0.024 & 0.034 & 0.1272 & 0.015 \\
\hline $\mathrm{Mn}^{2+}$ & 0.0026 & 0.0073 & 0.0112 & 0.036 & 0.0437 & 0.01 \\
\hline $\mathrm{Cu}^{2+}$ & 0 & 0.0003 & 0.0002 & 0.0015 & 0.0006 & 0.0007 \\
\hline $\mathrm{Zn}^{2+}$ & 0.002 & 0.0008 & 0.0017 & 0.0015 & 0.0019 & 0.0005 \\
\hline $\mathrm{NO}_{3}{ }^{-}$ & 8.05 & 8 & 11.98 & 14.37 & 17.25 & 16.0 \\
\hline $\mathrm{H}_{2} \mathrm{PO}_{4}^{-}$ & 2.30 & 2 & 0.99 & 1.93 & 2.25 & 1.25 \\
\hline $\mathrm{SO}_{4}{ }^{2-}$ & 3.02 & 2 & 3.48 & 2.12 & 2.72 & 1.4 \\
\hline $\mathrm{Cl}^{-}$ & 0 & 0.015 & 0 & 0 & 0.38 & 0 \\
\hline $\mathrm{B}(\mathrm{OH})_{4}^{-}$ & 0.009 & 0.037 & 0.04 & 0.0275 & 0.0313 & 0.025 \\
\hline $\mathrm{MoO}_{4}{ }^{2-}$ & 0 & 0.0003 & 0.0005 & 0.002 & 0.0006 & 0.0035 \\
\hline HEDTA & 0 & 0 & 0 & 0 & 0.12717 & 0 \\
\hline EDTA & 0 & 0.089 & 0.0238 & 0.0339 & 0 & 0 \\
\hline DTPA & 0 & 0 & 0 & 0 & 0 & 0.015 \\
\hline
\end{tabular}


TABLE 2. Chelation of the 12 standard solutions

\begin{tabular}{lcccc}
\hline Standard solution & $\begin{array}{l}\% \mathrm{Fe} \\
\text { precipitated } \\
\text { as }\end{array}$ & $\begin{array}{c}\% \mathrm{Cu} \\
\text { complexed } \\
\mathrm{Fe}_{2}\left(\mathrm{PO}_{4}\right)_{3}\end{array}$ & $\begin{array}{c}\% \mathrm{Zn} \\
\text { complexed }\end{array}$ & $\begin{array}{c}\% \mathrm{Mn} \\
\text { complexed }\end{array}$ \\
& 100 & - & - & - \\
\hline 1. Knop 1865 & 99.9 & - & - & - \\
2. Penningsfeld North Africa & 99.9 & - & - & - \\
3. Penningsfeld Carnations & - & - & - & - \\
4. Gravel culture Japan & 87.8 & 40.3 & 6.4 & 0.3 \\
5. Arnon and Hoagland 1940 & 4.0 & 97.5 & 97.5 & 0.1 \\
6. Dennisch R. Hoagland & 99.9 & - & - & - \\
7. Shive and Robbins 1942 & 4.0 & 99.3 & 42.4 & 0.2 \\
8. Hacskalyo 1961 & 4.9 & 99.5 & 48.8 & 0.2 \\
9. Steiner 1961 & 5.5 & 98.3 & 22.4 & 0.1 \\
10. Cooper 1979 & 6.9 & 100 & 99.2 & 7.7 \\
11. Res. Centre Soil. Cultures & 4.5 & 96.5 & 7.8 & 0 \\
12. Naaldwijk cucumber & & & & \\
\hline
\end{tabular}


TABLE 3. Chelating power of some synthetic chelates for the micro cations

\begin{tabular}{ll}
\hline Cation & Chelating power \\
\hline $\mathrm{Fe}^{3+}$ & EDDHA $>$ DTPA, CDTA $>$ EDTA $>$ EGTA, HEDTA $>$ NTA \\
$\mathrm{Cu}^{2+}$ & DTPA $>$ HEDTA, CDTA $>$ EDTA, EDDHA $>$ EGTA, NTA \\
$\mathrm{Zn}^{2+}$ & DTPA $>$ CDTA, HEDTA, EDTA $>$ NTA $>$ EGTA \\
$\mathrm{Mn}^{2+}$ & DTPA, CDTA $>$ EDTA, EGTA, HEDTA $>$ NTA \\
\hline
\end{tabular}

Adapted from Norvell W.A., 1972. 
TABLE 4. Distance from each standard solution to the overall mean

\begin{tabular}{|c|c|c|c|c|c|c|}
\hline $\begin{array}{l}\text { Standard } \\
\text { solution }\end{array}$ & $\begin{array}{l}\text { Knop } \\
1865\end{array}$ & $\begin{array}{l}\text { Pennings- } \\
\text { feld North } \\
\text { Africa }\end{array}$ & $\begin{array}{l}\text { Pennings- } \\
\text { feld } \\
\text { Carnations }\end{array}$ & $\begin{array}{l}\text { Gravel } \\
\text { culture } \\
\text { Japan }\end{array}$ & $\begin{array}{l}\text { Arnon and } \\
\text { Hoagland } \\
1940\end{array}$ & $\begin{array}{l}\text { Dennisch R. } \\
\text { Hoagland } \\
\text { USA }\end{array}$ \\
\hline $\begin{array}{l}\text { Distance in } \\
\text { proportions }\end{array}$ & 0.19 & 0.31 & 0.04 & 0.10 & 0.12 & 0.18 \\
\hline $\begin{array}{l}\text { Standard } \\
\text { solutions }\end{array}$ & $\begin{array}{l}\text { Shive and } \\
\text { Robbins } \\
1942\end{array}$ & $\begin{array}{l}\text { Hacskalyo } \\
1961\end{array}$ & $\begin{array}{l}\text { Steiner } \\
1961\end{array}$ & $\begin{array}{l}\text { Cooper } \\
1979\end{array}$ & $\begin{array}{l}\text { Research } \\
\text { Centre Soil- } \\
\text { less Cultures }\end{array}$ & $\begin{array}{l}\text { Naaldwijk } \\
\text { cucumber }\end{array}$ \\
\hline $\begin{array}{l}\text { Distance in } \\
\text { proportions }\end{array}$ & 0.35 & 0.19 & 0.17 & 0.05 & 0.12 & 0.16 \\
\hline
\end{tabular}


TABLE 5. $\mathrm{pH}$ and total ionic strength of the 12 standard solutions

\begin{tabular}{lccc}
\hline Standard solution & $\mathrm{pH}$ & $\begin{array}{c}\text { Nutrient } \\
\text { concentration } \\
(\mathrm{mmol} / \mathrm{l})\end{array}$ & $\begin{array}{c}\text { Nutrient } \\
\text { concentration } \\
(\mathrm{meq} / \mathrm{l})\end{array}$ \\
\hline Knop 1865 & 4.9 & 21.26 & 27.61 \\
Penningsfeld North Africa & 4.2 & 14.70 & 17.37 \\
Penningsfeld Carnations & 4.6 & 28.03 & 35.15 \\
Gravel culture Japan & 4.9 & 35.04 & 43.18 \\
Arnon and Hoagland 1940 & 4.7 & 31.16 & 40.27 \\
Dennisch R. Hoagland & 4.8 & 30.21 & 36.31 \\
Shive and Robbins 1942 & 4.6 & 23.41 & 32.80 \\
Hacskalyo 1961 & 4.4 & 21.36 & 28.82 \\
Steiner 1961 & 5.3 & 29.89 & 40.13 \\
Cooper 1979 & 4.8 & 32.70 & 41.41 \\
Res. Centre Soill. Cultures & 4.2 & 41.31 & 51.71 \\
Naaldwijk cucumber & 4.7 & 33.39 & 40.29 \\
\hline
\end{tabular}




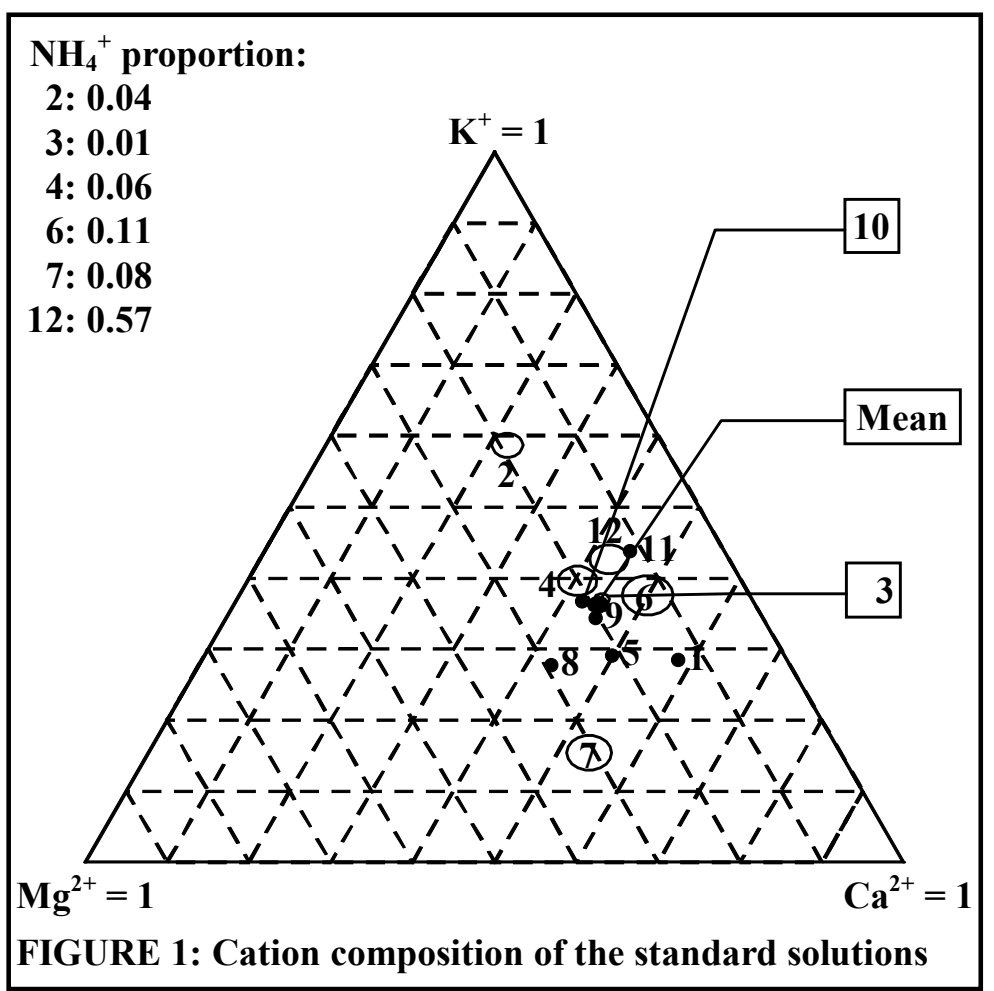

$\underline{\text { Standard solutions: }}$

1. Knop

2. Penningsfeld N. Africa

3. Penningsfeld Carnations

4. Gravel culture, Japan

5. Arnon and Hoagland

6. Dennish R. Hoagland

7. Shive and Robbins

8. Hacskalyo

9. Steiner

10. Cooper

11. Res. Centre Soil. Cult.

12. Naaldwijk, cucumber 


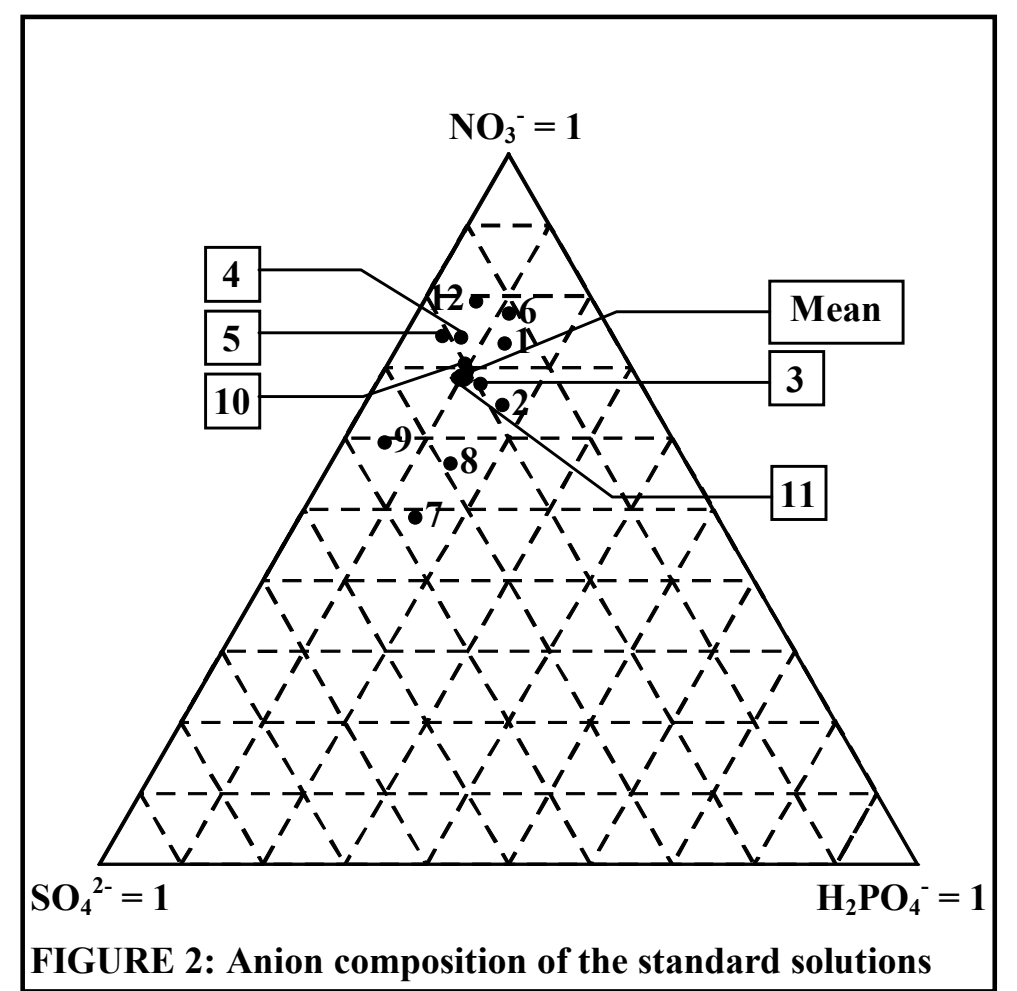

\section{$\underline{\text { Standard solutions: }}$}

1. Knop

2. Penningsfeld N. Africa

3. Penningsfeld Carnations

4. Gravel culture, Japan

5. Arnon and Hoagland

6. Dennish R. Hoagland

7. Shive and Robbins

8. Hacskalyo

9. Steiner

10. Cooper

11. Res. Centre Soil. Cult.

12. Naaldwijk, cucumber 